\title{
TELL ME YOUR STORY AND I WILL TELL YOUR SALES: A TOPIC MODEL ANALYSIS OF NARRATIVE STYLE AND FIRM PERFORMANCE ON ETSY
}

\section{Donato Cutolo, Simone Ferriani and Gino Cattani}

\begin{abstract}
Strategy scholars have widely recognized the central role that narratives play in the construction of organizational identities. Moreover, storytelling is an important strategic asset that firms can leverage to inspire employees, excite investors and engage customers' attention. This chapter illustrates how advancements in computational linguistic may offer opportunities to analyze the stylistic elements that make a story more convincing. Specifically, we use a topic model to examine how narrative conventionality influences the performance of 78,758 craftsmen selling their handmade items in the digital marketplace of Etsy. Our findings provide empirical evidence that effective narratives display enough conventional features to align with audience expectations, yet preserve some uniqueness to pique audience interest. By elucidating our approach, we hope to stimulate further research at the interface of style, language and strategy.
\end{abstract}

Keywords: Topic modelling; narrative; conventionality; digital market; craftsmanship; Etsy

Aesthetics and Style in Strategy

Advances in Strategic Management, Volume 42, 119-138

(C) Donato Cutolo, Simone Ferriani, and Gino Cattani. Published by Emerald Publishing Limited. This chapter is published under the Creative Commons Attribution (CC BY 4.0) licence. Anyone may reproduce, distribute, translate and create derivative works of this article (for both commercial \& non-commercial purposes), subject to full attribution to the original publication and authors. The full terms of this licence may be seen at http://creativecommons.org/licences/by/4.0/ legalcode

All rights of reproduction in any form reserved

ISSN: 0742-3322/doi:10.1108/S0742-332220200000042005 


\section{INTRODUCTION}

That individuals differ in their style of speaking and writing is hardly a novel observation. In particular, style is a building block of narrative as a genre, as elements of style inform how stories are constructed and interpreted (Wales, 1989). The concept of narrative style is not undisputed and it has evolved over time (Bradford, 1997), but in its essence, it encompasses the large variety of symbolic and aesthetic choices that identify the distinctive and recurring characteristics of authors and their works (Godart, 2018; Sgourev \& Althuizen, 2014). For example, a writer may choose to describe a given event using colourful words and unusual syntax, or in more formal language. Thus, the same exact story can be told with different stylistic nuances, each emphasizing different perspectives and features. Emblematic in this respect is 'Exercises in Style', Raymond Queneau's 1947 postmodern masterpiece. This book contains a collection of 99 retellings of the same unexceptional story - the author observes a man complaining in a bus and later, in another part of town, he sees the same man being advised by a friend to get an additional button for his coat. Each version has its own characterization expressed through not only linguistic variations, e.g., anagrams and metaphors, but also variations of perspective, like looking at the story backwards or in a dream-like fashion. The aggregate effect of these configurations of choices (some large, most small) on the creation constitutes its style. When such a pattern of choices expresses a consistent and recognizable manner of creation, the style may be thought of as a distinctive identity footprint (but even less-consciously produced artefacts/ behaviours may have definable styles, to the extent that they express a consistent and recognizable manner of creation). Indeed, forms of textual fingerprinting have long been employed to uniquely trace the origin of narrative materials to their authors. Analyses of word structure, for example, have been used to distinguish letters written by soldiers in 1800 (Broehl \& McGee, 1981), to establish the identity of the authors of biblical works, and to discriminate the speaking approaches of different political leaders (Foster, 1996).

Thus, the way people write and talk have been recognized as markers of individual identity and, as a consequence, as powerful judgement device (Pennebaker \& King, 1999). After all, we size people up at a glance based on their style; we know which styles we like and which we do not; we can almost instantaneously say when the styles of two books or songs are similar or different, and this aesthetic perception affects how we respond to it long before any conscious reasoning. This simple intuition, not only that individuals convey unique identities through their narrative styles but they also elicit unique meaning and responses among target audiences informs the research questions that animate this methodological essay. How to detect patterns of words usage over different topics in a way that is both empirically tractable and theoretically meaningful? Can we trace such patterns to individual performance differences? 
To answer these questions, finding patterns that describe observable textual differences is not enough. Rather, we must pay equal attention to the role of the reader (i.e., the audience) and try to appreciate the meaning that constitutes the reading experience or, in other words, what the audience gets from it. We achieve this goal by employing a topic modelling approach (a methodology to discover the latent structure of large collections of texts) to the detection of stylistic features in a sample of over 75,000 biographical narratives in the digital marketplace of Etsy and examining how such style relates to market performance. After fleshing out the topic structure of this population - consisting of the topics, the distribution of topics per document and the distribution of words over topics - we develop an original measure of stylistic conventionality informed by work on institutional conformity and explore the performance effect of narrative conventionality. We set this analytical effort within the growing literature attesting to the importance of storytelling in organizational life (Alvesson \& Kärreman, 2000).

Our evidence suggests that a moderate level of conventionality is associated to higher performance, suggesting that a narrative balancing typical and atypical element signals a more appealing identity to the relevant audiences. In contrast, when the presence of conventional features increases significantly, stories lose their ability to pique interest and curiosity, and those conventional elements in the narratives prevent sellers from effectively contrasting the anonymity of the digital marketplace. Overall, these findings resonate with the notion of 'legitimate distinctiveness' (Navis \& Glynn, 2011), suggesting that the broader narrative context provides frames of reference that entrepreneurs appropriate in their identity claims and narrative styles are a way for communicating adherence to or departure from such normative guideposts.

The essay is organized as follows. First, we briefly introduce storytelling in managerial and organizational studies, focussing particularly on the role of narrative style. Second, we delineate our topic modelling approach to the construction of conventionality-based measure of narrative style. Next, we discuss the findings from applying our analytical strategy to a large sample of 78,758 creative entrepreneurs selling their craft items in the Etsy digital marketplace. We conclude by advancing some theoretical as well as methodological considerations for researchers interested in the interface between style, language and management.

\section{NARRATIVES AND STYLE}

Our interest in detecting narrative styles and studying their effect on relevant organizational outcomes is part and parcel of a growing trend among scholars in the social sciences to rethink and reclaim their subjects from textual and linguistic points of view. In particular, although it 'took some time before the linguistic turn in the social sciences found its way into organization studies' (van Werven, Bouwmeester, \& Cornelissen, 2015, p. 629), growing research in strategy and entrepreneurship now takes a narrative approach to the study of performance and 
innovation. A key emphasis in these studies is that business leaders, as skilled rhetoricians, are able - through their storytelling tactics - to shape the sense making process of key stakeholders. For instance, stories are extremely important for entrepreneurial ventures to overcome the liability of newness and garner legitimacy (Navis \& Glynn, 2011). By conveying a comprehensible identity, entrepreneurial narratives shape the expectation of critical resource providers such as investors and customers, and reduce the uncertainty that typically surround new business initiatives (Garud, Schildt, \& Lant, 2014; Lounsbury \& Glynn, 2001; Manning \& Bejarano, 2017; Martens, Jennings, \& Jennings, 2007; van Werven et al., 2015).

Narrative style may play a critical role in this expectations-shaping process by interfering with the cognitive processing of the message itself. The theoretical basis for this suggestion lies in language expectancy theory, which holds that individuals develop normative expectations concerning appropriate communication styles in given situations (Burgoon, 1995; Burgoon, Denning, \& Roberts, 2002; Burgoon \& Miller, 1985), and such expectations affect individuals' attitude towards message persuasion. In this regard, the pattern of stylistic choices locates each work within a broader frame of reference, cultural, temporal or geographic, that inevitably shape and set audience expectations (Sgourev \& Althuizen, 2014). When those expectations are matched the persuasiveness of the message increases. Conversely, when they are violated, individuals can become distracted redirecting their attentional-related resources to non-task-related efforts. Indeed, attentional resources have limited capacity, such that when a cognitive task consumes the attentional resources of working memory impairment in performance on such task is bound to happen.

Expected patterns of language use have been shown by cognitive studies to exist (Ashcraft, 1989) and operate along multiple language features including language intensity, complexity and emotional tone (Appel, Schreiner, Haffmans, \& Richter, 2019; Averbeck \& Miller, 2014; Burgoon \& Miller, 1985; Craig \& Blankenship, 2011). Along these lines, past research has linked the frequency with which we use certain style words categories with how we are perceived by others, thereby resulting in tangible performance outcomes such as job performance or recruitment (Berry, Pennebaker, Mueller, \& Hiller, 1997). More recently, entrepreneurship scholarship has shown crowdfunding audiences to be sensitive to the linguistic styles adopted by entrepreneurs to describe their ideas on crowdfunding platforms (Parhankangas \& Renko, 2017; but see also Manning \& Bejarano, 2017).

In this chapter, we follow the lead of these studies to investigate the performance implications of adopting narrative styles that vary in their levels of conventionality. We surmise that conventional narratives are less likely to interfere with the audience ability to process the information conveyed in the narrative. In contrast, the unexpected nature of unconventional narratives will likely interfere with the cognitive processing of the content of the narrative. This weakened level of message processing should reduce audiences' persuasion by the narrative or, as in our setting, lower the audiences' willingness to make the purchase advocated in the message, resulting in reduced performance. 


\section{A TOPIC MODELLING APPROACH TO INVESTIGATE NARRATIVE STYLE}

The interest in measuring narrative stylistic features set its roots back in the early attempts of computer scientists to develop stylistic profiles of authors analyzing the frequencies of different word-type used in their works (Burrows, 1987; Holmes, 1994). These approaches were aimed at statistically quantifying stylistic features to derive a sort of fingerprint of each author. Progress in computer and data science, in particular in the field of computational linguistic, has made available more advanced and sophisticated tools to analyze the style of narration. In this section, we propose a topic modelling approach to derive the stylistic conventionality of entrepreneurial narratives and then investigate its impact on firms' performance.

Increasingly, management and organizational scholars are borrowing from computer science new methods to analyze language in large data collections. New computer-based language processing techniques reduce the high complexity of examining large text corpora, and offer novel approaches to study linguistic and stylistic features that afford a better understanding of the role of language in organizational dynamics. Among those tools, topic modelling has provided an interesting twist to the linguistic turn in management (DiMaggio, Nag, \& Blei, 2013; Hannigan et al., 2019). Topic models are defined 'generative models for documents' (Steyvers \& Griffiths, 2007, p. 424), as they make the latent thematic structure of textual data emerge. The basic assumption behind this methodology is that any documents is a combination of different topics where each topic represents a probability distribution over words (Mohr \& Bogdanov, 2013). Specifically, analyzing co-location and co-occurrence of words within documents, the models infer the underlying topics and their relative weight in the corpus of data.

This work applies Latent Dirichlet Allocation topic models (Blei, Ng, \& Jordan, 2003) to study the style of the narratives. Specifically, this essay provides an empirical application of how to use a topic model approach to compute a measure of conventionality and test how conventional styles in entrepreneurial narratives influence performance.

\section{EMPIRICAL APPLICATION}

\section{Example Data}

For the application of our approach to dissect narrative stylistic features, we focus on entrepreneurial narratives shared by craftsmen selling their products in the digital marketplace of Etsy. Founded in 2005, Etsy is a digital platform for creative small businesses, where people can set up their virtual shop and sell their handmade items, craft supplies and vintage goods. The company aims at providing 'creative entrepreneurs' (i.e., the sellers as defined in the company website) with opportunities to pursue their business ideas. This empirical setting is well-suited for the purpose of this study, as stories are particularity relevant in the 
world of crafting as they infuse the items with both symbolic and material value (Mishler, 1992).

Also, the digital marketplace under study provides access to a rich set of information: along with performance data, Etsy strongly encourages sellers to write a biography to introduce themselves, and share the story of their business, since each virtual shop has a dedicated web page that offers an overview of the business. Web-scraping methods were used to collect the narratives of these entrepreneurs every two months. After a year, we decided to build a cross-sectional dataset with the last scraping because less than $1 \%$ of the sellers in the sample actually modified the narrative during the entire time span. The final sample consisted of 78,758 sellers with processed and validated narratives.

\section{Topic Model Results}

Although several approaches have been proposed, there is no consensus on the best way to determine the optimal number of topics in the model. For the purposes of this essay, we followed the conventional practice to constrain this number to 100 (Blei \& Lafferty, 2007; Haans, 2019; Kaplan \& Vakili, 2015). A representation of all the topics is provided in Table 1, where for each topic we report its relative weight and the five most representative words.

The emerging pattern of topics well captures relevant features of the context under investigation, thus confirming the contextual embeddedness of these entrepreneurial narratives (Gartner, 2007; Lounsbury \& Glynn, 2001). Unsurprisingly, we observe that a number of topics emphasize the presence in the narratives of typical business elements such as the description of the products sold (e.g., Topic 77: 'jewelry', 'bead', 'piece', 'bracelet', 'necklace' and Topic 4: 'furniture', 'build', 'home', 'design', 'table') or cues that convey the ability to create value, such as focus on quality and customers assistance (e.g., Topic 93: 'quality', 'product', 'item', 'handmade', 'unique' and Topic 55: 'custom', 'order', 'question', 'contact', 'message'). At the same time, it is quite interesting to point out the appearance of typical features of narrative accounts, such as topics that resonate loudly with personal characteristics, roles and the journey of each entrepreneurs (Topic 68: 'home', 'family', 'mom', 'daughter', 'husband' or Topic 27: 'start', 'years', 'ago', 'open', 'store').

Additionally, the weights of topics within the different product categories exposes narrative elements that persist significantly across them (e.g., Topic 88: 'make', 'love', 'thing', 'idea', 'enjoy' or Topic 67: 'create', 'passion', 'creative', 'share', 'dream'), suggesting a general effort at building resonance with the expectations of the intended audience of customers (Martens et al., 2007). In fact, these topics perfectly match the general characteristics of the marketplace, since Etsy places great emphasis on such features as creativity, uniqueness and craftsmanship, consistently with Etsy's mission statement:

Etsy is the global marketplace for unique and creative goods. It's home to a universe of special, extraordinary items, from unique handcrafted pieces to vintage treasures. (Etsy website) 
Table 1. Two Examples of Narrative-topics Distribution.

\begin{tabular}{|c|c|c|c|c|}
\hline Narrative & \multicolumn{4}{|c|}{ Topics Distribution } \\
\hline \multicolumn{5}{|l|}{ Once upon a time there was a whiney guy from } \\
\hline $\begin{array}{l}\text { California where he met a Winey Girl. The } \\
\text { whiney guy enjoyed drinking Miller Lite whilst }\end{array}$ & $0 \%$ & $10 \%$ & $20 \%$ & $30 \%$ \\
\hline cheering on his beloved Detroit Lions on Sunday & Topic 9 & & & \\
\hline $\begin{array}{l}\text { afternoons. The Winey Girl wasn't sure a } \\
\text { relationship with a beer drinking Michigonian }\end{array}$ & Topic 10 & & & \\
\hline would ever last but bought a 12 pack of Miller & Topic 23 & & & \\
\hline $\begin{array}{l}\text { Lite and gave it a try. Eventually the } 12 \text { pack was } \\
\text { gone and the Whiney Guy was still there so they }\end{array}$ & Topic 42 & & & \\
\hline $\begin{array}{l}\text { uncorked a bottle of wine to celebrate and soon he } \\
\text { became a Winey Guy. }\end{array}$ & Topic 49 & & & \\
\hline Winey Guy decided to quit the remodel & Topic 63 & & & \\
\hline $\begin{array}{l}\text { construction work and start his own business } \\
\text { creating furniture and unique home décor items }\end{array}$ & Topic 70 & & & \\
\hline out of repurposed wine barrels, appropriately & Topic 83 & & & \\
\hline $\begin{array}{l}\text { named The Winey Guys and now three years and } \\
1,200 \text { barrels later the Winey Guy is still at it, } \\
\text { creating beautiful pieces each and every day for all }\end{array}$ & Topic 90 & & & \\
\hline
\end{tabular}
of you. Be sure to follow us on social media to keep up with all of our latest creations and find out the next chapter of our story!

In July 2019, we will celebrate our 19th year in business. I personally have been collecting model trains for over $50+$ years, and wanted to take my hobby and turn it into a business. So...Several years ago, I decided to get my trains out of their boxes and up on display. I built a $12^{\prime} \times 20^{\prime}$ room for all my model trains. I wanted my toy trains displayed without having support brackets, so I designed an aluminum display shelving system. It held my heaviest locomotives without any trouble. I soon realized other people may have a need for my model railroad display shelves, and that is when I began selling online.

Soon afterward, I started making hand crafted buildings, bridges and accessories for my train room from up-cycled materials (from local companies) and also listed them for sale. They were a success!

We continue to expand since a lot of our products are purchased for fairy gardens, weddings, and party favors. We welcome custom orders of our products and we accept challenges for new ones. Our number one key to success is making sure our customers are always happy. We go out of our way to ensure low prices and prompt shipping at the best cost.

We have been featured on television, in magazines and news articles for all of our top-quality products.

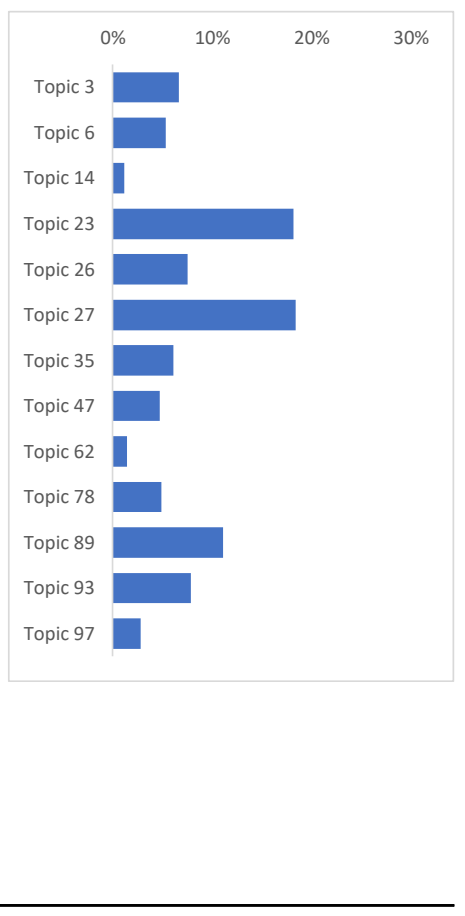

Notes: Only topics that account for $1 \%$ or more of the narrative are reported. $* p<0.05 ; * * p<$ $0.01 ; * * * p<0.001 . N=78,758$. 
Other topics, on the contrary, are very specific of a single product category e.g., Topic 46: 'food', 'cake', 'make', 'cookie', 'bake' presents mainly in the category which groups people who sell Food \& Drink items, or Topic 62: 'doll', 'toy', 'child', 'play', 'kid', that substantially appears only in the Toys category. Data produced with topic modelling also include the distribution of topics over each document, which offers a fine-grained description of narratives' stylistic composition. To illustrate, Table 1 reports the topic composition of two narratives by two sellers both listing their items in the Home Improvement product category.

Apart from the number of topics present in each narrative (which is influenced also by the length of the narrative), topic distribution reveals two different narrative styles. The first story revolves around the way this seller became a wine aficionado after meeting his current wife and how this transformation sparked his entrepreneurial journey. The author places great emphasis on Topic 70: 'drink', 'wine', 'beer', 'glass', 'tea' - which accounts for $25 \%$ of the entire story - and Topic 49: 'wife', 'business', 'family', 'husband', 'team' - which covers another $16 \%$ of the narrative.

The second narrative is less concentrated in terms of topic distribution, incorporating more elements and touching on a multiplicity of aspects. The author narrates how he turned his model train hobby into a business, but here the process is centred upon the active role of customers' need in shaping the business (Topic 27: 'start', 'year', 'ago', 'decide', 'sell', Topic 23: 'furniture', 'build', 'home', 'decide', 'custom', and Topic 35: 'order', 'item', 'ship', 'contact', 'purchase'). The story also reports the company's attempt to build a solid brand renowned for high-quality products through appearances on magazines and television show, which is well captured by a significant presence of Topic 89 ('product', 'design', 'company', 'line', 'brand') and Topic 93 ('make', 'quality', 'product', 'high', 'design').

\section{Narrative Conventionality}

The topic model data produce several interesting insights. Although this approach does not allow to fully appreciate all the stylistic features of a text, the distribution of topics within narratives sheds light on similarities and differences between stories. For instance, some entrepreneurs in this digital context are more prone to introducing personal elements in their narratives as potential differentiating elements at the expenses of a purer and more prototypical storyline. Additionally, the diffusion of the topics within and across product categories is a clear indication of elements, practices and thus meanings, that define the context: the higher the weight of a topic in a product category, the stronger its relevance in that context.

Starting from these considerations, we combined the narrative-topic with the topic-product category distribution to build our measure of narrative conventionality. Elaborating on the intuition of Durand and Kremp (2016), we used the distribution of topics over narratives to conceptualize narrative stylistic conventionality as a systematic tendency to include topics that are widely diffused and shared also by other sellers in the same product category. We adapted the 
measure developed by Durand and Kremp to our data, regressing the topic shares of narrative for each seller on the topic shares of all the other seller within the same product category. More formally,

$$
\text { Tin }=\hat{\alpha} \cdot \bar{T} i+b \hat{\imath}+u i c \text { with } E(u i c)=0
$$

where Tin represent the weight of topic I for narrative $n$ and $\bar{T} i$ is the average weight of topic I for all the other narrative in the category. We took the slope of the regression line as our measure of content conventionality, with all the values above 1 indicating a conventional narrative.

$$
\text { Narrative Conventionality }=\widehat{\alpha}=\operatorname{Co\nu }(T n, \bar{T}) \operatorname{VAR}(\bar{T})
$$

In other words, a narrative is conventional if the author overemphasizes topics, and thus features, that are also central in other sellers' narratives. Fig. 1 offers an illustration of the structure of a conventional narratives vis-a-vis a nonconventional one.

In this example, the red bars represent the topics distribution across all the members of the Video Games product category, while the blue and the green bars report the narrative-topics distribution of two sellers operating in that category. Looking at Fig. 1, we observe that highly influent topics in narrative \# 2 - such as Topic 7, Topic 22, Topic 56 and Topic 94 - are also widely shared and diffused among the other sellers within the same category. On the contrary, narrative \# 1 is not centred around these elements as it emphasizes other topics - like Topic, 25, Topic 32, Topic 35 and Topic 74 - that are less relevant in other sellers' narratives. Based on our measure, narrative \# 1 is considered unconventional, while narrative \# 2 has a more conventional style.

\section{VARIABLES}

\section{Dependent Variable}

Craft Items Sold: Because the focus of this chapter is on the impact that conventional narratives have on performance, we measure performance in terms of craft items sold. Thus, the dependent variable in this study is a count of the items sold by each seller since s/he joined the platform.

\section{Independent Variables}

Narrative Conventionality: The main variable of this chapter is the stylistic conventionality of the narrative measured as described in the previous section. We also include its squared term to test for nonlinear relationship. To address multicollinearity issues arising from the interaction terms, this variable was meancentred prior to being interacted (Aiken, West, \& Reno, 1991).

\section{Control Variables}

We included several control variables in the analysis to account for other factors that may influence sellers' performance in this context. Two key control variables 


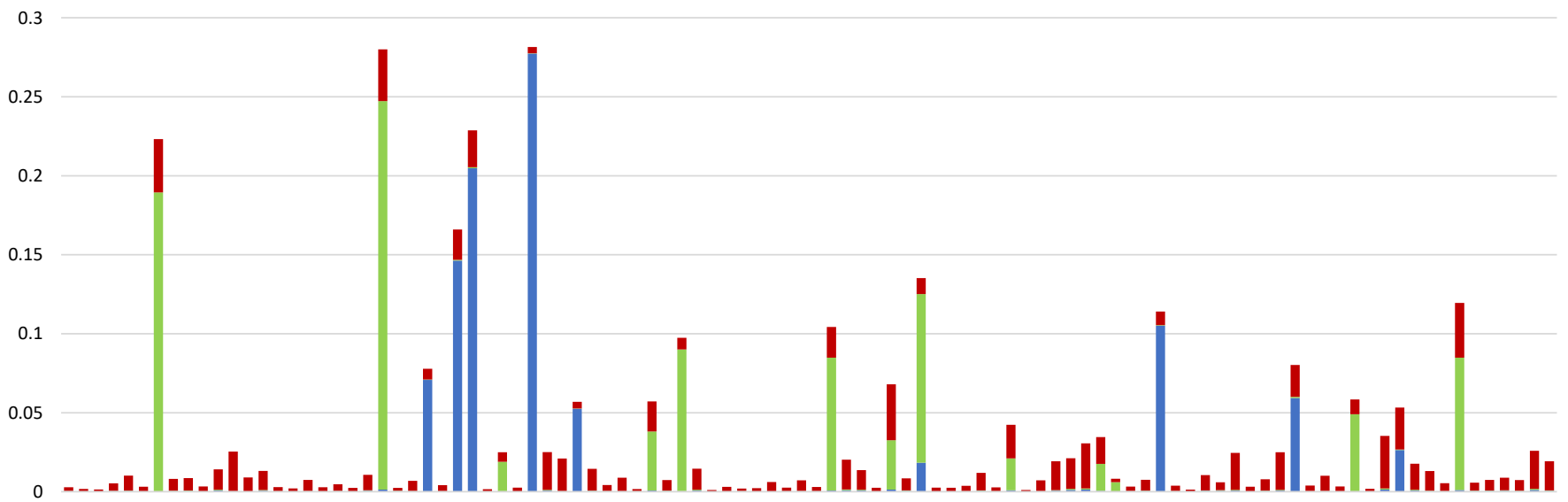

$\begin{array}{lllllllll} & \end{array}$ Narrative \#1 Narrative \#2 — Product Category: Video Games 
were taken into consideration: seller rating, measured as the average review score received by a seller, and platform experience, measured as the numbers of years selling on the platform. We also controlled for the length of the narrative, measured in terms of number of words, and the average level of competition in the product category. Finally, we introduced a set of dummy variables to control for gender and country of origin of the sellers and the product categories they selected to sell their items.

\section{MODEL SPECIFICATION}

We adopted a negative binomial regression rather than a Poisson model because the dependent variable of this study, number of craft items sold, is a nonnegative count variable with over dispersion (Hausman, Hall, \& Griliches, 1984). Further, robust estimators were used to control for mild violation of underlying assumptions (Cameron \& Trivedi, 1998). The baseline model includes only the control variables, in Model 1 we introduce narrative conventionality and its squared term.

\section{RESULTS}

Descriptive statistics and pairwise correlations for all variables are provided in Table 2. The means and SDs were calculated using untransformed measures for ease of interpretation.

All the correlations in the data are reasonably low, and we controlled for multicollinearity using Variance Inflation Factors (VIFs). Results show a mean VIF of 3.49, with the highest VIF of 9.01 (Product Category Shoes), which is still below the recommended threshold of 10 (Hair, Black, Babin, \& Anderson, 2010). Thus, multicollinearity is unlikely to influence the results in our analyses. Results are presented in Table 3.

In the Baseline Model, we find that entrepreneurs with better ratings $(\beta=$ $0.604, p<0.001)$ and with more years of experience on the platform $(\beta=0.222$, $p<0.001)$ are more likely to sell a higher number of items. Moreover, we find that the level of competition in product categories negatively influences the number of products sold $(\beta=-0.589, p<0.001)$, and that male sellers slightly outperform their female counterparts $(\beta=-0.032, p<0.05)$. Finally, the strategic relevance of narratives is highlighted by the positive and significant narrative length coefficient $(\beta=0.032, p<0.05)$ : articulated and rich narratives increase the likelihood of attracting audience attention.

Turning to the variable of theoretical interest, Model 1 introduces narrative conventionality and its squared. When controlling for other relevant factors, our analysis reveals a positive and significant effect of narrative conventionality $(\beta=$ $0.133, p<0.001$ ), as well as a negative and significant effect of its squared term on seller performance $(\beta=-0.056, p<0.001)$. Following Lind and Mehlum (2010), we validate the presence of an inverted $U$ shape by testing the slopes at both the ends of the data range. The slope at the lower bound $(-1.85)$ is positive and significant $(0.341, p<0.001)$ and at the upper bound (4.46) is negative and significant 
Table 2. Descriptive Statistics and Correlation Matrix.

\begin{tabular}{|c|c|c|c|c|c|c|c|c|c|c|c|}
\hline Variables & Mean & SD & Min. & Max. & 1 & 2 & 3 & 4 & 5 & 6 & 7 \\
\hline 1. Craft Items Sold & $1,744.28$ & $3,020.26$ & 0 & $1,630,579$ & 1 & & & & & & \\
\hline 2. Seller Rating & 4.57 & 1.27 & 0 & 5 & 0.065 & 1 & & & & & \\
\hline 3. Platform Experience & 5.07 & 2.8 & 0 & 14 & 0.1621 & 0.1376 & 1 & & & & \\
\hline 4. Category Competition & $2,838.33$ & 648.49 & 924 & 4,469 & -0.084 & -0.0043 & 0.0109 & 1 & & & \\
\hline 5. Gender (Female) & 0.65 & 0.48 & 0 & 1 & -0.0098 & 0.0176 & 0.0153 & 0.0276 & 1 & & \\
\hline 6. Narrative Length & 203.10 & 128.07 & 39 & 1,640 & 0.0324 & 0.0316 & 0.108 & 0.0332 & 0.0054 & 1 & \\
\hline 7. Narrative Conventionality & 1.05 & 0.67 & -0.80 & 5.52 & 0.0054 & -0.0129 & -0.0636 & 0.0129 & 0.0299 & -0.0621 & 1 \\
\hline
\end{tabular}


Table 3. Negative Binomial Regression Models.

\begin{tabular}{|c|c|c|c|c|}
\hline \multirow[b]{2}{*}{ Dep. Variable: Craft Items Sold } & \multicolumn{2}{|c|}{ Baseline Model } & \multicolumn{2}{|l|}{ Model 1} \\
\hline & Coeff. & Robust Std. Err & Coeff. & Robust Std. Err \\
\hline Seller Rating & $0.604 * * *$ & 0.007 & $0.605 * * *$ & 0.007 \\
\hline Platform Experience & $0.222 * * *$ & 0.003 & $0.223 * * *$ & 0.003 \\
\hline Category Competition (Log) & $-0.589 * * *$ & 0.059 & $-0.578^{* * *}$ & 0.059 \\
\hline Gender & $-0.032 *$ & 0.016 & $-0.037^{*}$ & 0.016 \\
\hline Narrative Length (Log) & $0.031 *$ & 0.014 & $0.037 * *$ & 0.014 \\
\hline Narrative Conventionality & & & $1.133^{* * *}$ & 0.013 \\
\hline Narrative Conventionality $^{2}$ & & & $-0.055^{* * *}$ & 0.009 \\
\hline Nationality & \multicolumn{2}{|l|}{ Yes } & \multicolumn{2}{|l|}{ Yes } \\
\hline Product Category & \multicolumn{2}{|l|}{ Yes } & \multicolumn{2}{|l|}{ Yes } \\
\hline Constant & $2.566 * * *$ & 0.083 & $2.550 * * *$ & 0.083 \\
\hline Lnalpha & \multicolumn{2}{|r|}{0.465} & \multicolumn{2}{|r|}{0.462} \\
\hline Log Pseudo Likelihood & \multicolumn{2}{|c|}{-635142.54} & \multicolumn{2}{|c|}{-635002.79} \\
\hline Wald Chi-Square (d.f.) & \multicolumn{2}{|c|}{$39,651.17(129)$} & \multicolumn{2}{|c|}{$40,071.17(131)$} \\
\hline$p$ value & \multicolumn{2}{|r|}{0.000} & \multicolumn{2}{|r|}{0.000} \\
\hline
\end{tabular}

Notes: $* p<0.05 ; * * p<0.01 ; * * * p<0.001$.

$(-0.364, p<0.001)$, resulting in a significant overall test for the presence of an inverted $U$ shape $(t$-value $=4.76 ; p<0.001)$. Furthermore, the estimated turning point is located within data range $(1.19,95 \%$ Fieller interval $[0.92 ; 1.66])$. To facilitate the interpretation of the results, in Fig. 2, we plot the predicted number of followers across the range of observed values for narrative conventionality.

While holding all the other variables in the model constant, the presence of contextually familiar elements in the narrative is associated with a $14.2 \%$ increase

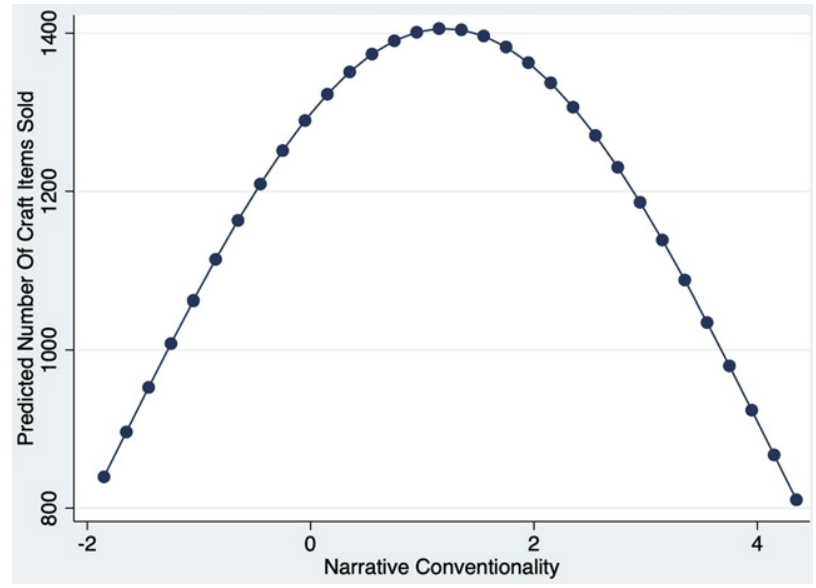

Fig. 2. Narrative Conventionality - Craft Items Sold Relationship. Marginal Effects Estimated by Keeping the Other Covariates at Their Means. 
$(=\exp (0.133)-1)$ in the number of items sold for moderate levels of narrative conventionality. For higher levels of conventionality, on the contrary, the same increase leads to a $5.4 \%$ decrease $(=\exp (-0.055)-1)$ in the sales. In other words, for an average seller on the platform, the benefits of the optimal level of narrative conventionality translates into 567 more craft items sold compared to those who do not display enough conventional features in their stories (at the minimum value of narrative conventionality, and in 610 more items compared to those sellers who are extremely conventional in presenting their stories (at the maximum value of conventionality).

\section{DISCUSSION AND CONCLUSION}

Over the past few years, a large and growing body of research has studied the role storytelling (stories or narratives) plays in organizational dynamics (Alvesson \& Kärreman, 2000; Bartel \& Garud, 2009; Garud, Dunbar, \& Bartel, 2011; Martin, 2016; Petkova, 2016; Vaara \& Tienari, 2011; Vaara, Sonenshein, \& Boje, 2016). Narratives are ubiquitous in organizational settings, as they represent a powerful device that allows individuals and organizations to enact the environment they face (Bruner, 1991; Martin, Patterson, \& Price, 1979), as well as a means to cultivate the interaction with external and internal audiences (Gaytán, 2019; Martens et al., 2007; Martin, 2016). To illustrate, Petkova (2016) shows how online organizations gain moral legitimacy by constructing narratives that align their desired identity and their technical skills and then translate those stories into acceptable commercial practices to garner practical legitimacy. To this date, however, we lack a systematic understanding of how narratives are actually constructed to appeal to various audiences. In this regard, innovation and entrepreneurship literature offers fruitful indications (e.g., Garud \& Gehman, 2012; Garud \& Giuliani, 2013; Martens et al., 2007; Navis \& Glynn, 2011). Indeed, one of the key challenges innovators (e.g., entrepreneurs) face is to persuade relevant audiences (e.g., crowdfunders, venture capitalists, angel investors, funding organizations, R\&D managers, users and so on) to support their novel ideas. The skillful use of linguistic devices has been recognized as critical to deal with this challenge (Aldrich \& Fiol, 1994; Czarniawska-Joerges, 1997; Gabriel, 2004; Larrimore, Jiang, Larrimore, Markowitz, \& Gorski, 2011; Martin, 2016; van Werven et al., 2015). Manning and Bejarano (2017), for instance, found that entrepreneurs may apply different more or less project-specific narrative styles to mobilize resources. ${ }^{1}$ Their

\footnotetext{
${ }^{1}$ Analyzing 54 crowdfunding campaigns on the platform Kickstarter, Manning and Bejarano found that campaigns tend to use and/or combine two dominant narrative styles that they call the 'ongoing journey' and the 'results-in-progress' style. As they put it: 'The former style narrates projects as longer-term endeavours powered by creative initial ideas and a bold vision, inviting audiences to "join the journey"; the latter narrates projects more narrowly as a progression of accomplishments, engaging the audience instrumentally to support next steps' (Manning \& Bejarano, 2017, p. 194).
} 
findings are particularly relevant for our study because they reveal how narratives may be related to the ability or inability of crowdfunding campaigns to align presentations with narrative styles that are expected of projects sharing certain features.

Building on this narrative perspective, the main goal of this chapter was to offer a concise methodological contribution by introducing a topic model approach for the study of narrative stylistic features. Recent advances in quantitative methodologies for analyzing large-scale heterogeneous data have enabled novel understanding of increasingly complex narrative structures. For instance, Min and Park (2019) have shown how a narrative lends itself naturally to network-based modelling and analysis that can be further enriched by incorporating various text analysis methods from computational linguistics. ${ }^{2}$ We believe that topic modelling and, more generally, natural language processing hold great promise for the study of narratives and have the potential to advance our understanding of how different stylist choices influence important organizational and economic outcomes. The progress of computer science, therefore, offers researchers more opportunities to explore the characteristics that make a story more or less effective in persuading the internal and external public.

While previous studies have looked at the temporal construction of narratives and how narratives reflect key project features, our focus is on the stylistic conventionality of entrepreneurial narratives - that is, the systematic tendency to include topics that are widely diffused and shared also by other entrepreneurs in the same product category. Specifically, we analyze the stories of craftsmen selling their handmade products on Esty, the largest digital marketplace for handmade and craft items, and we test how the conventionality of narratives can affect their performance. The adoption of a topic model approach reveals that, in this context, stories embody personal elements of the seller's life, but also that entrepreneurs seek to conform to established contextual standards by incorporating topics that are widely shared and diffused among other sellers.

The growing interest in narratives, as well as the type of narrative style that is more or less effective in eliciting the support from relevant audiences, rests on the recognition that narratives are critical strategic assets that established organizations and entrepreneurs can leverage to generate identities and differentiate themselves from their competitors. Narratives are indeed essential for building identities (White, 1981), and by controlling them, actors can leverage them to gain visibility and be perceived as distinctive (Aspers, 2010). It is through the stories they tell about themselves - who they are, what they do and why they do it - that entrepreneurs try to project an identity that is similar enough to that of other entrepreneurs, but not too similar to go unnoticed. In his study of outsider artists, for instance, Alan Fine (2004) found that many art collectors share artists'

\footnotetext{
${ }^{2}$ They apply the methods to Victor Hugo's Les Misérables. As they put it: 'We model the temporally unfolding nature of narrative as a dynamical growing network of nodes and edges representing characters and interactions, which allows us to characterize the story progression using the network growth pattern' (Min \& Park, 2019, p. 1).
} 
biographical stories with visitors when they display their $\operatorname{art}^{3}$ By the same token, narratives that incorporate biographical accounts might add to the perceived uniqueness of an entrepreneur's product offering.

Since the style of a narrative is critical for mobilizing symbolic and/or material support, the performance implications of adopting certain narratives in entrepreneurial processes deserve greater attention (Manning \& Bejarano, 2017; Martens et al., 2007). Our study's main findings suggest how the right level of conventionality of a narrative can be leveraged strategically to enhance distinctiveness while displaying a degree of conformity to topics that are diffused and shared by others in the same product category and that audience members expect to hear. Specifically, narratives that differ in their level of conventionality have a differential impact on firm performance (i.e., product sales). This chapter represents a first step towards a more systematic analysis of the performance implications of adopting certain narratives in entrepreneurial processes.

The use of topic modelling holds the promise to shed important light on how narratives can be built to attract audiences. Other methodological approaches, however, also appear to be suitable for examining the style of a narrative in analytic terms. A very promising methodology for studying and measuring style and stylistic changes is social sequence analysis (SSA). A recently developed methodological tool, the analysis of social sequences affords the study of patterns of social processes over time in an eventful way similar to historiography, while retaining social scientific abstraction (Abbott, 1990; Stark \& Vedres, 2006). One of the distinctive features of SSA is to account for uniqueness and similarity at the same time. Formilan, Ferriani and Cattani (2020) have exposed the contribution of SSA methodological framework to the study of temporal patterns of creativity in the underground electronic music field by examining artists' stylistic variation sequences. Examining the stylistic trajectories of electronic music artists, they have shown how sequence methods can be leveraged to represent and analyze temporal dynamics of style in a way that other traditional analytical approaches (e.g., event history or panel design methods) cannot. The use of SSA could be further extended to trace temporal patterns of stylistic changes in a company's narratives to establish how those changes make these narratives more or less effective in persuading internal and external audiences over time.

Given the vast diffusion of narratives and storytelling in organization life, and the increased availability of data, the approach proposed here could be fruitfully applied to other empirical settings. For instance, in the cultural and creative domains, stories are crucial not only to encourage engagement and foster participation (Adipa, 2019) but also to create shared meanings between consumers and producers (Petkova, 2016; Wohl, 2019). The proliferation of digital and social media has strengthened this ongoing interaction between producers and consumers by affording novel spaces and opportunities to build a

\footnotetext{
${ }^{3}$ As one collector explained: 'In many cases with this work, the story is more important than the art is, and people are buying the story as opposed to the piece of art for art's sake ... There are artists I've supported financially just because I like them, and I like their story, but not because I believe the pieces are outstanding' (in Fine, 2004, p. 68).
} 
relationship through stories. To illustrate, the key of the success of The Blonde Salad blog was the selectivity of its founder - Chiara Ferragni - in choosing the brands to work with because 'the stories Ferragni would tell about these brands had to reflect her own lifestyle' (Keinan, Maslauskaite, Crener, \& Dessain, 2015, p. 5, emphasis not in the original). Given the proliferation of blogs, the style of the bloggers' narrative is becoming increasingly a critical differentiating factor. Tracing narratives over time, including the way they are communicated, would reveal which stylistic features contribute to determining their appeal in the eyes of blog followers.

Entrepreneurial pitches represent another very interesting area of application. Indeed, most of what we know about entrepreneurship comes from stories of and about entrepreneurs. A growing body of research in entrepreneurship now adopts a framing approach to study creativity and innovation, where framing refers to 'the use of rhetorical devices in communication to mobilize support and minimize resistance to a change' (Cornelissen \& Werner, 2014, p. 185). Despite the frequency with which audiences across innovation domains are expected to evaluate novel ideas, however, little research still exists that attends to the structural properties of such narratives and their effect on the recipients' evaluative responses. Recently, scholars have explored the impact of abstract or concrete linguistic framings on how relevant audiences evaluate entrepreneurial pitches (e.g., Falchetti, Cattani, \& Ferriani, 2018). The study of the frames innovators employ in their pitches could be further expanded by using topic modelling to analyze more systematically how innovators can use rhetorical devices - particularly the topics that form a narrative and the style by which this narrative is communicated to the target audiences - to mobilize the resources they need.

With online digital platforms becoming increasingly viable contexts for entrepreneurial activities, future research may find these settings particularly attractive for studying the implications of different narrative styles. Indeed, these platforms provide unique access to an impressive amount of textual and performance data that could be used to gauge the effectiveness of different narrative stylistic features. In this chapter, we have attempted to make a first step in this direction, with the hope to stimulate further research in using our approach to study how different stylistic choices affect effective communication.

\section{REFERENCES}

Abbott, A. (1990). A primer on sequence methods. Organization Science, 1(4), 375-392.

Adipa, P. (2019). Talking events: How social interaction and discourse shape cultural participation, aesthetic evaluation, and meaning-making. Poetics, 77, 101381. doi:10.1016/j.poetic.2019.101381

Aiken, L. S., West, S. G., \& Reno, R. R. (1991). Multiple regression: Testing and interpreting interactions. Thousand Oaks, CA: Sage Publications.

Aldrich, H. E., \& Fiol, C. M. (1994). Fools rush in? The institutional context of industry creation. Academy of Management Review, 19(4), 645-670. doi:10.5465/amr.1994.9412190214

Alvesson, M., \& Kärreman, D. (2000). Taking the linguistic turn in organizational research: Challenges, responses, consequences. The Journal of Applied Behavioral Science, 36(2), 136-158. doi: $10.1177 / 0021886300362002$ 
Appel, M., Schreiner, C., Haffmans, M.-B., \& Richter, T. (2019). The mediating role of eventcongruent emotions in narrative persuasion. Poetics, 77, 101385. doi:10.1016/ j.poetic. 2019.101385

Ashcraft, M. H. (1989). Human memory and cognition. Glenview, IL: Scott, Foresman \& Co.

Aspers, P. (2010). Orderly fashion: A sociology of markets. Princeton, NJ: Princeton University Press.

Averbeck, J. M., \& Miller, C. (2014). Expanding language expectancy theory: The suasory effects of lexical complexity and syntactic complexity on effective message design. Communication Studies, 65(1), 72-95. doi:10.1080/10510974.2013.775955

Bartel, C. A., \& Garud, R. (2009). The role of narratives in sustaining organizational innovation. Organization Science, 20(1), 107-117. doi:10.1287/orsc.1080.0372

Berry, D. S., Pennebaker, J. W., Mueller, J. S., \& Hiller, W. S. (1997). Linguistic bases of social perception. Personality and Social Psychology Bulletin, 23(5), 526-537.

Blei, D. M., \& Lafferty, J. D. (2007). Correction: A correlated topic model of science. Annals of Applied Statistics, 1(2), 634. doi:10.1214/07-AOAS136

Blei, D. M., Ng, A. Y., \& Jordan, M. I. (2003, January). Latent dirichlet allocation. Journal of Machine Learning Research, 3, 993-1022.

Bradford, R. (1997). Stylistics. Abingdon: Routledge.

Broehl, W. G., \& McGee, V. E. (1981). Content analysis in psychohistory: A study of three lieutenants in the Indian mutiny, 1857-58. Journal of PsychoHistory, 8(3), 281.

Bruner, J. (1991). The narrative construction of reality. Critical Inquiry, 18(1), 1-21. doi:10.1086/ 448619

Burgoon, M. (1995). Language expectancy theory: Elaboration, explication, and extension. In C. R. Berger \& M. Burgoon (Eds.), Communication and Social Influence Processes (pp. 29-52). East Lansing, MI: Michigan State University Press.

Burgoon, M., Denning, V., \& Roberts, L. (2002). Language expectancy theory. In J. P. Dillard \& M. Pfau (Eds.), The persuasion handbook: Developments in theory and practice (pp. 117-136). Thousand Oaks, CA: Sage Publications.

Burgoon, M., \& Miller, G. R. (1985). An expectancy interpretation of language and persuasion. In H. Giles \& R. St. Clair (Eds.), Recent advances in language, communication, and social psychology (pp. 199-229). Abingdon: Routledge.

Burrows, J. F. (1987). Word-patterns and story-shapes: The statistical analysis of narrative style. Literary and Linguistic Computing, 2(2), 61-70. doi:10.1093/1lc/2.2.61

Cameron, A. C., \& Trivedi, P. K. (1998). Regression analysis of count data. Cambridge: Cambridge University Press.

Cornelissen, J. P., \& Werner, M. D. (2014). Putting framing in perspective: A review of framing and frame analysis across the management and organizational literature. The Academy of Management Annals, 8(1), 181-235. doi:10.5465/19416520.2014.875669

Craig, T. Y., \& Blankenship, K. L. (2011). Language and persuasion: Linguistic extremity influences message processing and behavioral intentions. Journal of Language and Social Psychology, 30(3), 290-310.

Czarniawska-Joerges, B. (1997). Narrating the organization: Dramas of institutional identity. Chicago, IL: University of Chicago Press.

DiMaggio, P., Nag, M., \& Blei, D. (2013). Exploiting affinities between topic modeling and the sociological perspective on culture: Application to newspaper coverage of U.S. government arts funding. Poetics, 41(6), 570-606. doi:10.1016/j.poetic.2013.08.004

Durand, R., \& Kremp, P.-A. (2016). Classical deviation: Organizational and individual status as antecedents of conformity. Academy of Management Journal, 59(1), 65-89. doi:10.5465/ amj.2013.0767

Falchetti, D., Cattani, G., \& Ferriani, S. (2018). Overcoming the liability of novelty: The power of framing. Academy of Management Proceedings, 2018(1), 11077. doi:10.5465/AMBPP.2018. 11077abstract

Fine, G. A. (2004). Everyday genius: Self-taught art and the culture of authenticity. Chicago, IL: University of Chicago Press; University Presses Marketing. Retrieved from https:// www. overdrive. $\mathrm{com} / \mathrm{search}$ ? =911F9497-CE05-489B-919F-3E91F622DFA6 
Formilan, G., Ferriani, S., \& Cattani, G. (2020). A methodological essay on the application of social sequence analysis to the study of creative trajectories. In V. Dörfler \& M. Stierand (Eds.), Handbook of research methods on creativity. Cheltenham: Edward Elgar. Retrieved from https://openaccess.city.ac.uk/id/eprint/20164/

Foster, D. (1996). Primary culprit: Who is anonymous. The New York Times Magazine, 29, 50-57.

Gabriel, Y. (2004). Narratives, stories and texts. In D. Grant, C. Hardy, C. Oswick, \& L. Putnam (Eds.), The Sage handbook of organizational discourse (Vol. 61, p. 77). Los Angeles, CA: Sage.

Gartner, W. B. (2007). Entrepreneurial narrative and a science of the imagination. Journal of Business Venturing, 22(5), 613-627. doi:10.1016/j.jbusvent.2006.10.003

Garud, R., Dunbar, R. L. M., \& Bartel, C. A. (2011). Dealing with unusual experiences: A narrative perspective on organizational learning. Organization Science, 22(3), 587-601. doi:10.1287/ orsc. 1100.0536

Garud, R., \& Gehman, J. (2012). Metatheoretical perspectives on sustainability journeys: Evolutionary, relational and durational. Research Policy, 41(6), 980-995. doi:10.1016/j.respol.2011.07.009

Garud, R., \& Giuliani, A. P. (2013). A narrative perspective on entrepreneurial opportunities. Academy of Management Review, 38(1), 157-160. doi:10.5465/amr.2012.0055

Garud, R., Schildt, H. A., \& Lant, T. K. (2014). Entrepreneurial storytelling, future expectations, and the paradox of legitimacy. Organization Science, 25(5), 1479-1492. doi:10.1287/orsc.2014.0915

Gaytán, M. S. (2019). Extending authenticity: Going corporate in a craft market. Poetics, 77, 101380. doi:10.1016/j.poetic.2019.101380

Godart, F. C. (2018). Why is style not in fashion? Using the concept of "style" to understand the creative industries. In C. Jones \& M. Maoret (Eds.), Research in the sociology of organizations (Vol. 55, pp. 103-128). Bingley: Emerald Publishing Limited. doi:10.1108/S0733558X20180000055005

Haans, R. F. J. (2019). What's the value of being different when everyone is? The effects of distinctiveness on performance in homogeneous versus heterogeneous categories. Strategic Management Journal, 40(1), 3-27. doi:10.1002/smj.2978

Hair, J. F., Black, W. C., Babin, B. J., \& Anderson, R. E. (2010). Multivariate data analysis (7th ed.). Upper Saddle River, NJ: Prentice-Hall.

Hannigan, T., Haans, R. F. J., Vakili, K., Tchalian, H., Glaser, V., Wang, M., ... Jennings, P. D. (2019). Topic modeling in management research: Rendering new theory from textual data. The Academy of Management Annals. doi:10.5465/annals.2017.0099

Hausman, J., Hall, B., \& Griliches, Z. (1984). Econometric models for count data with an application to the patents-R\&D relationship (No. t0017). Cambridge, MA: National Bureau of Economic Research. doi:10.3386/t0017

Holmes, D. I. (1994). Authorship attribution. Computers and the Humanities, 28(2), 87-106.

Kaplan, S., \& Vakili, K. (2015). The double-edged sword of recombination in breakthrough innovation: The double-edged dword of Recombination. Strategic Management Journal, 36(10), 1435-1457. doi:10.1002/smj.2294

Keinan, A., Maslauskaite, K., Crener, S., \& Dessain, V. (2015). The blonde salad (pp. 515-574). Boston, MA: Harvard Business School Case.

Larrimore, L., Jiang, L., Larrimore, J., Markowitz, D., \& Gorski, S. (2011). Peer to peer lending: The relationship between language features, trustworthiness, and persuasion success. Journal of Applied Communication Research, 39(1), 19-37.

Lind, J. T., \& Mehlum, H. (2010). With or without U? The appropriate test for a U-shaped relationship. Oxford Bulletin of Economics and Statistics, 72(1), 109-118.

Lounsbury, M., \& Glynn, M. A. (2001). Cultural entrepreneurship: Stories, legitimacy, and the acquisition of resources. Strategic Management Journal, 22(6-7), 545-564. doi:10.1002/smj.188

Manning, S., \& Bejarano, T. A. (2017). Convincing the crowd: Entrepreneurial storytelling in crowdfunding campaigns. Strategic Organization, 15(2), 194-219. doi:10.1177/1476127016 648500

Martens, M. L., Jennings, J. E., \& Jennings, P. D. (2007). Do the stories they tell get them the money they need? The role of entrepreneurial narratives in resource acquisition. Academy of Management Journal, 50(5), 1107-1132. doi:10.5465/amj.2007.27169488 
Martin, S. R. (2016). Stories about values and valuable stories: A field experiment of the power of narratives to shape newcomers' actions. Academy of Management Journal, 59(5), 1707-1724. doi:10.5465/amj.2014.0061

Martin, J., Patterson, K., \& Price, R. (1979). The effects of level of abstraction of a script on accuracy of recall, predictions and beliefs. Research paper No. 520. Graduate School of Business, Stanford University.

Min, S., \& Park, J. (2019). Modeling narrative structure and dynamics with networks, sentiment analysis, and topic modeling. PloS One, 14(12), 1-20.

Mishler, E. G. (1992). Work, identity, and narrative: An artist-craftsman's story. In G. C. Rosenwald \& R. L. Ochberg, Storied lives. The cultural politics of self-understanding (pp. 21-40). New Haven, CT: Yale University Press.

Mohr, J. W., \& Bogdanov, P. (2013). Introduction-topic models: What they are and why they matter. Poetics, 41(6), 545-569. doi:10.1016/j.poetic.2013.10.001

Navis, C., \& Glynn, M. A. (2011). Legitimate distinctiveness and the entrepreneurial identity: Influence on investor judgments of new venture plausibility. Academy of Management Review, 36(3), 479-499. doi:10.5465/amr.2008.0361

Parhankangas, A., \& Renko, M. (2017). Linguistic style and crowdfunding success among social and commercial entrepreneurs. Journal of Business Venturing, 32(2), 215-236. doi:10.1016/ j.jbusvent.2016.11.001

Pennebaker, J. W., \& King, L. A. (1999). Linguistic styles: Language use as an individual difference. Journal of Personality and Social Psychology, 77(6), 1296-1312. doi:10.1037/00223514.77.6.1296

Petkova, I. (2016). Between high-tech and high-fashion: How E-Commerce fashion organizations gain moral and pragmatic legitimacy in the fashion field. Poetics, 57, 55-69. doi:10.1016/ j.poetic. 2016.04.001

Sgourev, S. V., \& Althuizen, N. (2014). "Notable" or "not able": When are acts of inconsistency rewarded? American Sociological Review, 79(2), 282-302. doi:10.1177/0003122414524575

Stark, D., \& Vedres, B. (2006). Social times of network spaces: Network sequences and foreign investment in Hungary. American Journal of Sociology, 111(5), 1367-1411.

Steyvers, M., \& Griffiths, T. (2007). Probabilistic topic models. Handbook of Latent Semantic Analysis, $427(7), 424-440$.

Vaara, E., Sonenshein, S., \& Boje, D. (2016). Narratives as sources of stability and change in organizations: Approaches and directions for future research. The Academy of Management Annals, 10(1), 495-560. doi:10.5465/19416520.2016.1120963

Vaara, E., \& Tienari, J. (2011). On the narrative construction of multinational corporations: An antenarrative analysis of legitimation and resistance in a cross-border merger. Organization Science, 22(2), 370-390. doi:10.1287/orsc.1100.0593

Wales, K. (1989). A dictionary of stylistics (1st ed.). Abingdon: Routledge.

van Werven, R., Bouwmeester, O., \& Cornelissen, J. P. (2015). The power of arguments: How entrepreneurs convince stakeholders of the legitimate distinctiveness of their ventures. Journal of Business Venturing, 30(4), 616-631.

White, H. C. (1981). Where do markets come from? American Journal of Sociology, 87(3), 517-547. doi: $10.1086 / 227495$

Wohl, H. (2019). Creative visions: Presenting aesthetic trajectories in artistic careers. Poetics, 76, 101358. doi:10.1016/j.poetic. 2019.03 .003 